Simulation-based training improved short-term test performance among Ethiopian medical trainees.

\section{G555(P) QUALITY IMPROVEMENT IN ENDOTRACHEAL INTUBATION IN A PAEDIATRIC EMERGENCY DEPARTMENT: CHECKLIST DEVELOPMENT AND IMPLEMENTATION USING SIMULATION AND ACTION CARDS}

HC Taekema Landham, T Wood, S Hollis, M Shepherd. Children's Emergency Department, Starship Hospital, Auckland, New Zealand

\subsection{6/archdischild-2015-308599.505}

Background Endotracheal intubation in paediatric emergency medicine is a relatively infrequent event with a significant complication rate. Strong evidence exists for the use of checklists around emergency intubations to improve safety.

This QI project took place in a dedicated Children's Emergency Department (CED), seeing 33000 presentations a year. Our institution takes part in the National Emergency Airway Registry for Children (NEAR4KIDS), an international, multicentre advanced airway registry and quality improvement initiative. Measures such as number of attempts to successful advanced airway placement, saturation changes during RSI and tracheal intubation-associated adverse events are being used to regularly evaluate airway management within each participating institution. Out-of-theatre endotracheal intubation data has been captured since March 2013. Previously, we successfully increased inconsistent end-tidal CO2 use to almost 100\% after a quality improvement push based on NEAR4KIDS data. No intubation checklist was used at our institution until December 2014, when an Emergency Intubation Checklist was implemented in our Paediatric Intensive Care Unit (PICU) and CED. It was deemed important to create a hospital-wide checklist. This would promote team coherence for CED emergency intubations, when often both PICU and CED staff are involved. PICU sees around 150 intubations annually; CED intubates around 25 children a year. The team members' familiarity with advanced airway management is therefore potentially very different.

Method We decided on a step-wise, simulation-based checklist development and implementation. Step 1 involved identifying key checklist elements, using other intubation checklists and expert opinions from within our institution and externally. Step 2 involved developing a checklist of essential actions and tasks based on the roles of the airway team members. Step 3 involved running low-fidelity simulated scenarios using the checklist with the CED Nurse Educators. Step 4 consisted of medium-fidelity simulation training for CED junior doctors. We amended the checklist based on feedback given by the Nurse Educators and CED doctors. Step 3 and 4 elucidated the need for a tool to speed up and aid preparation for intubation prior to completing the checklist. A solution was found in creating role-specific action cards for airway team members: event manager, airway doctor, airway assistant, medication nurse, circulation nurse. These are laminated A5 size cards, stating a role and its actions required to prepare for intubation. Step 5 involved introduction of the intubation quality improvement package to all CED staff, using a variety of simulated scenarios aimed at each level of nursing and medical staff involved in advanced airway management. The final step is assessment of the QI tool's effect on patient care, with adaptations actioned as needed.
Results Introduction of this quality improvement package has been well received. Team member feedback (both nursing and medical) was uniformly positive. The cards aided role allocation, allowed speedier preparation for intubation and promoted role flexibility. The effects on patient outcome are measured as part of the Near 4 kids airway collaboration. We anticipate being able to report some simulation based results over the next 3 months.

Conclusion A shared checklist for PICU and ED appears to be helpful. Involvement of all levels of medical and nursing staff in the development of this quality improvement tool ensured buyin. Simulation-based introduction of an intubation checklist in a low-volume setting such as a paediatric emergency department allows timely implementation. Action cards are an excellent way to teach and reinforce checklist-related roles. Effect on patient outcomes will be reported in the near future.

\section{G556(P) IS MEAN BLOOD SUGAR MONITORING WITH SMART METRE A BETTER INDICATOR OF CONTROL THAN HBA1C IN PAEDIATRIC DIABETES?}

${ }^{1} \mathrm{R}$ Pujara, ${ }^{2} \mathrm{H}$ Kannappan, ${ }^{2} \mathrm{G}$ Margabanthu. ${ }^{1}$ Paediatric, University Hospitals of Leicester NHS Trust, Leicester, UK; ${ }^{2}$ Paediatric, Kettering General Hospital NHS Trust, Kettering, UK

\subsection{6/archdischild-2015-308599.506}

Context Kettering General Hospital, Distric Hospital, United Kingdom. Number of paediatric patients with type 1 diabetes 140 .

Multidisciplinary Team: Paediatric Diabetes Specialist Consultant, paediatric registrars, diabetic nurses, dietician.

Problem For paediatric diabetes patients, effective glucose control with less variability is always challenging. Inadequate control can lead to recurrent hospital admissions affecting patient's quality of life.

Assessment of problem and analysis of its causes MDT identified following potential causes for inadequate control.

1. Clinic HbA1C is performed 4 times a year to monitor glycaemic control but it may not truly reflect day to day control of patient's blood sugar levels at home which can be significantly up and down.

2. Maintaining a hand written sugar diary can be difficult for patients with compliance issues.

3. Interpretation of an inadequately filled paper diary can be challenging for doctors as well as patients as it does not give an idea of trends of sugar levels and therefore does not reflect glycaemic control and variability.

4. Patients can also experience difficulties in calculating right dose of insulin at home.

Intervention Patients were provided SMART metres after an education about their use.

They were taken through a process of on-going learning to review and analyse the SMART metre downloads and make appropriate changes to their insulin needs to prevent high and low sugars.

The MDT had an oversight of the process to actively facilitate the learning to decrease admissions aiming for diabetes home care.

In 3 monthly clinics near patient HbA1c testing as well as SMART metre downloads were used to analyse patient compliance and treatment results

Study design Prospective data collection during clinics from January to June 2014. 
A retrospective analysis of prospectively collected database of blood sugar downloads from SMART metres and near patient A1C tests.

Strategy for change Change was implemented through education with MDT approach. Families were supported through the process of changing metres and offered open access to MDT.

Measurement of improvement The effect of the planned changes were measured by patient confidence in self-management, glycaemic control, Variability of blood sugars versus A1C levels and need for hospital admissions.

Better understanding amongst the patients of their own control led to the patient empowerment in a friendlier home environment.

Mean A1C for 100 downloads was $61.67 \mathrm{mmol} / \mathrm{mol}(9.8$ $\mathrm{mmol} / \mathrm{L}$ ) that was comparable to a mean blood sugar of 9.6 $\mathrm{mmol} / \mathrm{L}$ with a mean standard deviation of 4.7 . However this correlation changed when the data was stratified based on Standard deviation (SD).

1. $\mathrm{SD}<2$ : mean $\mathrm{A} 1 \mathrm{C}$ was $45.7 \mathrm{mmol} / \mathrm{mol}(7.6 \mathrm{mmol} / \mathrm{L})$ compared to average mean blood sugar $5.53 \mathrm{mmol} / \mathrm{L}$.

2. SD 2-4: co-related to mean A1C $53.9 \mathrm{mmol} / \mathrm{mol}(8.7 \mathrm{mmol} /$ L) to average mean blood sugar $7.9 \mathrm{mmol} / \mathrm{L}$.

3. $\mathrm{SD}>4$ : mean $\mathrm{A} 1 \mathrm{C} 63.4 \mathrm{mmol} / \mathrm{mol}(10 \mathrm{mmol} / \mathrm{L})$ and average mean blood sugars- $9.97 \mathrm{mmol} / \mathrm{L}$ were exactly same.

4. $\mathrm{SD}>6$ : mean $\mathrm{A} 1 \mathrm{C}$ of $73.89 \mathrm{mmol} / \mathrm{mol}(11.6 \mathrm{mmol} / \mathrm{L}) \mathrm{com}-$ pared to average mean blood sugar of $12.4 \mathrm{mmol} / \mathrm{L}$.

Admissions due to DKA and hypoglycaemia decreased by half. Effects of changes Better control closer to home improving patient experience and quality of life at reduced heath care cost.

There was initial hesitation around new metre and tight targets which was overcome by education, close supervision and reflection.

Lessons learnt SMART metre download review is a good way of analysing blood sugars targets, variability and control over a period of time.

They are better predictors of glycaemic control

It has its advantages in empowering patients at the comfort of their own homes.

Message for others SMART metres have taken paediatric diabetes management closer to home.

Mean blood sugars are a better indicator of glycaemic control and variability when the standard deviation is between $0-4$.

\section{G557(P) ABSTRACT WITHDRAWN}

\section{G558(P) MANDATORY TEMPLATES FOR PAEDIATRIC TRANSFER LETTERS: REDUCING RISK AND IMPROVING PATIENT CARE}

FM Cust, S Goldring, E Yule, S Saldien, J Patel, M Lee, Y Zhou, R Ajitsaria. Paediatrics, Hillingdon Hospital, Uxbridge, UK

\subsection{6/archdischild-2015-308599.507}

Background Deficient transfer letters are widely recognised as a significant cause of increased risk. ${ }^{1}$ Following a coroner's enquiry which cited a suboptimal transfer letter as a factor in delayed medical intervention, the Hillingdon Hospital Paediatric department introduced a standardised template and a powerful quality improvement project began.
Methods A template was devised using APLS $^{2}$ and CATS 3 documents to identify gold standards. A retrospective audit was carried out, comparing 20 letters pre with 20 post template introduction. 29 key content points were compared. It included a range of trainee doctors filling in the forms and a range of different reasons, from PICU transfers to tertiary acute transfer for ongoing investigation. A telephone survey was then carried out to explore varying practice in 12 London Paediatric units.

Results Prior to introduction of template; only 12 of the 29 key information times were present over $75 \%$ of the time. With the template introduction; all 29 areas were identified over $75 \%$ of forms.

The template has resulted in significant improvement in sharing patient information across a number of areas, from patient demographics to current treatment. Examples include a $20 \%$ increase in communicating current medications which is a significant improvement $(\mathrm{p}<0.05)$, and a 50\% improvement in recording current working weight. Before the use of a template, 0/20 letters sampled provided information on allergy and immunisation, whereas letters using the template were over $90 \%$ compliant in these criteria.

Phone surveys of other London Paediatric units found only one of eight has a transfer template. It was reported transfer documentation was rushed, time-pressured and rarely involved consultant input.

Conclusion Using a concise template significantly improves the content of paediatric transfer letters. This simple intervention should in turn improve continuity of care and patient safety. The inclusion of a 'status at transfer' prompt improves governance regarding documentation of deteriorations during transit. The pathway within which each letter is approved and signed off by an attending consultant has also greatly increased senior input into these important communication documents.

Given the standard practice amongst London Hospitals being no formal template; we propose that a standardised template could be rolled out to all London Hospitals and beyond, to improve the handover of patients between hospitals.

\section{REFERENCES}

1 Delegation and referral. London: GMC, 2013

2 Samuels M, Wieteska S. Advance paediatric life support: the practical approach. 5th edn. Chichester: Wiley-Blackwell, 2011:261

3 Children's Acute Transfer Team. Referral Form. http://site.cats.nhs.uk/wp-content/ uploads/2012/08/Referrer_prompt_-sheet.pdf accessed 03/12/14

\section{G559(P) PAEDIATRIC COMMUNITY ACQUIRED PNEUMONIA - IMPROVING MANAGEMENT}

R Robertson, C McDonald. Paediatric Department, Buckinghamshire Healthcare NHS Trust, Stoke Mandeville, UK

\subsection{6/archdischild-2015-308599.508}

Context This project looked at management of Paediatric Community Acquired Pneumonia (CAP) within a District General Hospital and how the Paediatric Team could improve this.

Problem The British Thoracic Society (BTS) produced guidance in 2011 as to the management of Community Acquired Pneumonia.

Within our hospital it was noted that there was variation in management of CAP, both in terms of its investigation and treatment.

This project aimed to improve the management of CAP using the BTS Guidance as the gold standard. 